\title{
QUEEN'S
UNIVERSITY
BELFAST
}

\section{Industrial scale microwave processing of tomato juice using a novel continuous microwave system}

Stratakos, A. C., Delgado-Pando, G., Linton, M., Patterson, M. F., \& Koidis, A. (2016). Industrial scale microwave processing of tomato juice using a novel continuous microwave system. Food Chemistry, 190, 622628. https://doi.org/10.1016/j.foodchem.2015.06.015

\section{Published in: \\ Food Chemistry}

\section{Document Version:}

Peer reviewed version

Queen's University Belfast - Research Portal:

Link to publication record in Queen's University Belfast Research Portal

\section{Publisher rights}

(c) 2015 Elsevier. This manuscript version is made available under the CC-BY-NC-ND 4.0 licensehttp://creativecommons.org/licenses/by-ncnd/4.0/,which permits distribution and reproduction for non-commercial purposes, provided the author and source are cited.

\section{General rights}

Copyright for the publications made accessible via the Queen's University Belfast Research Portal is retained by the author(s) and / or other copyright owners and it is a condition of accessing these publications that users recognise and abide by the legal requirements associated with these rights.

Take down policy

The Research Portal is Queen's institutional repository that provides access to Queen's research output. Every effort has been made to ensure that content in the Research Portal does not infringe any person's rights, or applicable UK laws. If you discover content in the Research Portal that you believe breaches copyright or violates any law, please contact openaccess@qub.ac.uk. 
1 Industrial Scale Microwave Processing of Tomato Juice using a novel Continuous microwave system

3

4 Alexandros Ch. Stratakos ${ }^{\mathrm{a}}$, Gonzalo Delgado-Pando ${ }^{\mathrm{a}}$, Mark Linton ${ }^{\mathrm{b}}$, Margaret F. Patterson ${ }^{\mathrm{b}}$, 5 Anastasios Koidis ${ }^{\mathrm{a}, ~ *}$

6

7 a Queen’s University Belfast, Institute for Global Food Security, Belfast, Northern Ireland, 8 UK.

$9 \quad$ b Agri-Food \& Biosciences Institute, Belfast, Northern Ireland, UK.

* Corresponding author

14

15 Dr Anastasios (Tassos) Koidis

16 Institute for Global Food Security

17 Queen's University Belfast

18 18-30 Malone Road

19 Belfast, BT9 5BN

20 Northern Ireland, UK

21 Tel: +44 2890975569

22

email: t.koidis@qub.ac.uk 
Abstract

26 This study evaluated the effect of an industrial scale continuous flow microwave volumetric

27 heating system in comparison to conventional commercial scale pasteurisation for the processing of tomato juice in terms of physicochemical properties, microbial characteristics and antioxidant capacity. The effect against oxidative stress in Caco-2 cells, after in vitro digestion was also investigated. Physicochemical and colour characteristics of juices were very similar between technologies and during storage. Both conventional and microwave pasteurisation inactivated microorganisms and kept them in low levels throughout storage. $\mathrm{ABTS}^{+}$values, but not ORAC, were higher for the microwave pasteurised juice at day 0 however no significant differences between juices were observed during storage. Juice processed with the microwave system showed an increased cytoprotective effect against $\mathrm{H}_{2} \mathrm{O}_{2}$ induced oxidation in Caco-2 cells. Organoleptic analysis revealed that the two tomato juices were very similar. The continuous microwave volumetric heating system appears to be a viable alternative to conventional pasteurisation.

\section{Keywords}




\section{INTRODUCTION}

Tomato is one of the most popular and widely grown fruits in the world and a major component of the Mediterranean diet. Tomato has high concentrations of compounds with antioxidant potential such as vitamin C and carotenoids (Beecher, 1998). It is well accepted that the consumption of tomato and tomato products can result in the reduction of the risk of chronic diseases such as cardiovascular disease and cancer (Willcox, Catignani \& Lazarus 2003). Food antioxidants can scavenge the reactive oxygen species present in the human body and thus lower the oxidative damage in tissues (Willcox et al. 2003; Cilla, Laparra, Alegria, Barbera \& Farre 2008). Therefore, ensuring the retention of high amounts of these compounds after processing is important to maintain the health-giving properties of tomato products. Thermal processing is the most commonly used method to inactivate microorganisms and enzymes and prolong the shelf life of tomato juice. However, thermal processing can adversely affect the organoleptic characteristics, the nutrient content and the antioxidant capacity of foods (Igual, García-Martínez, Camacho \& Martínez-Navarrete 2011). Modern consumers demand products of high quality which are convenient, nutritious and minimally processed with fresh like characteristics (Hong \& Wang 2014). Because of these demands, the food industry is showing a greater interest in the adoption of novel food processing technologies (Señorans, Ibáñez \& Cifuentes, 2003). Food producers that want to minimise thermal damage and thus maintain or increase nutrient content, can achieve this mainly by improving the efficiency of heat delivery and temperature control. Contemporary conventional heating systems aim to achieve this but heating based on convection and conduction poses significant restrictions. Microwave heating is one of these novel thermal technologies that can be used as an alternative in order to achieve or possibly enhance tomato juice shelf life, quality and nutrient content. The main feature of microwave heating is the unique ability to generate heat from within a food matrix which is not feasible by any other 
conventional heating method (Fu 2004). In several cases, microwave processing has proven to be not only much quicker, but also capable of better preserving quality and nutritional characteristics (e.g. vitamin retention) compared to conventional heating technologies (Chandrasekaran, Ramanathan \& Basak 2013). One of the most important concerns of microwave heating is the non-uniform temperature distribution which can have implications in terms of safety as well as quality (Chandrasekaran et al. 2013). Volumetric and continuous systems are quite new to the market and utilise a unique delivery method of microwave energy to achieve a much greater penetration depth during processing (AMT, 2015). Although they claim to offer a viable alternative by achieving heating uniformity, decreasing processing times and offering operational advantages to the processor, the exact effect on product quality, safety and organoleptic properties has not been assessed properly in comparison with existing practices.

The determination of the bioaccessibility of bioactive compounds appears to be a more relevant indicator of the nutritional value of foods compared to their concentration in the food matrix (Knockaert, De Roeck, Lemmens, Van Buggenhout, Hendrickx, Van Loey, 2011). Therefore, understanding how a novel processing technology affects the bioaccessibility of bioactives is important in assessing this technology and to that extend, no data exists in the literature to date.

In this study, we assessed the application of a novel continuous microwave volumetric heating $(\mathrm{MVH})$ system to tomato juice, one of the most popular products that are processed worldwide, with conventional heating systems. The aim was to validate and compare the MVH system with conventional heat treatment with regards to operational characteristics, physicochemical, microbiological, nutritional and organoleptic characteristics both in situ and during storage. 


\section{MATERIALS AND METHODS}

\subsection{Sample preparation and preliminary trials}

Fresh ripe tomatoes (Dorothy variety) were purchased from a local supplier (Down Wholesale, U.K.). Tomatoes were washed, cut and pressed to obtain the juice using a packing press (100 P2 Voran Maschinen GmbH, Austria) industrial equipment. Preliminary trials were conducted in order to identify the appropriate pasteurisation conditions. The processing conditions chosen (see 2.2) were able to reduce the total viable counts (TVC) below the detection limit. All juice samples were stored at $4{ }^{\circ} \mathrm{C}$ for a period of 56 days and analysed on day $0,7,14,28$ and 56.

\subsection{Conventional and novel processing of tomato juice}

Conventional batch pasteurisation of tomato juice (CP) was performed with an industrial steam jacket kettle (Culino kettle, Hackman, Finland). The kettle was filled with $30 \mathrm{~L}$ of raw tomato juice and processed at a target temperature of $85^{\circ} \mathrm{C}$ for $5 \mathrm{~min}$, under a turbulent flow pattern with an overall processing time (including come-up time) of $20 \mathrm{~min}$. An emptying valve was used to collect samples which were immediately cooled down in ice. The product temperature was registered using a thermocouple connected to a data logger.

Microwave volumetric heating (MVH) of tomato juice was performed with an industrial continuous microwave system supplied by Advanced Microwave Technologies (AMT, Edinburgh, UK). The system comprises of a process tank, pump, pressure and temperature sensors, flow meter, rotation device and the MVH unit. The microwaves were produced by six magnetrons (6 x $3 \mathrm{~kW}$, total input $=18 \mathrm{~kW}$; $2450 \mathrm{MHz})$ placed in either side of the microwave transparent processing tube which operated at $85 \pm 0.4^{\circ} \mathrm{C}$ (Fig. 1). The feed pump supplied the system with a flow of $100 \mathrm{~L}$ of tomato juice per hour. The overall residence time 
of the juice inside the processing tube was $81.8 \pm 1.1 \mathrm{sec}$. The temperature was automatically

122

123

124

125

126

127

128

129

130

131

132

133

134

136

137

138

139

140

141

142

143

144

145

recorded before and immediately after treatment, as soon as the product left the processing tube. The pasteurised samples were collected in sterile containers and cooled down in iced water.

\subsection{Physicochemical analysis}

Moisture of the tomato juices was determined gravimetrically. Total soluble solids ( ${ }^{\circ}$ Brix) were measured using a refractometer (Eclipse, Bellingham + Stanley Ltd, UK). Measurements were performed at a stable temperature $\left(20^{\circ} \mathrm{C}\right)$. Titratable acidity was measured according to Adekunte et al. (2010). Results were reported in g citric acid/100 g sample. The $\mathrm{pH}$ of tomato juice samples was measured using a digital $\mathrm{pH}$ metre (Jenway 3510, U.K.). Serum cloudiness was evaluated according to Silva, Sato, Barbosa, Dacanal, Ciro-Velásquez, \& Cunha (2010). Briefly, the sample is centrifuged and the optical density of the supernatant is determined at $660 \mathrm{~nm}$. Colour measurements were performed with the use of a reflectance colorimeter (Minolta Chroma 173 Meter CR-410, Konica-Minolta, Basildon, U.K.) equipped with a CIE 1931 standard observer and D65 Illuminant. The juice was placed in glass cell made of optical glass with a $60 \mathrm{~mm}$ diameter and $38 \mathrm{~mm}$ depth. The CIELab system L*, a* and b* was followed. The chroma (C) parameter was also determined, $C=\left(a^{* 2}+b^{* 2}\right)^{1 / 2}$

\subsection{Light microscopy}

The microstructure of the tomato juices after processing was assessed using a CX41 light microscope (Olympus, U.K.). The samples were stained with toluidine blue and observed on a glass slide and evaluated using different magnifications. Representative images were taken with a digital video camera (JVC TK C1480BE). 


\subsection{ABTS and ORAC antioxidant capacity assays}

147 Tomato juice extract was obtained by vortexing $0.5 \mathrm{~g}$ freeze dried tomato juice in $10 \mathrm{ml} 80 \%$ ethanol at $2500 \mathrm{rpm}$ for $20 \mathrm{~min}$ and centrifuged for $10 \mathrm{~min}$ at $2500 \times \mathrm{g}$, prior to analysis. The ABTS radical-scavenging assay is based on the discolouration of the radical cation 3-ethylbenzothiazoline-6-sulfonic acid (ABTS•+; Sigma, UK.). The procedure was performed according to Miller et al. (1993) as improved by Re, Pellegrini, Proteggente, Pannala, Yang, \& Rice-Evans (1999). Absorbance was measured at $734 \mathrm{~nm}$ after $10 \mathrm{~min}$ incubation. The results were expressed as $\mu \mathrm{mol}$ Trolox equivalents per $\mathrm{g}$ of dried weight using an appropriate calibration curve. The oxygen radical absorbance capacity (ORAC) assay was performed according to Huang et al. (2005) with some modifications. Fluorescence of the samples was recorded for $100 \mathrm{~min}$ at 2 min intervals using a plate reader (Tecan, Safire 2190, UK). Excitation wavelength was set at $485 \mathrm{~nm}$ and emission wavelength at $530 \mathrm{~nm}$. ORAC values and the sample. Results were expressed as $\mu \mathrm{M}$ Trolox equivalents (TE) per g of dried weight.

\subsection{Microbiological analysis}

At each sampling interval, juice samples were opened aseptically and a suitable dilution series was prepared in maximum recovery diluent (MRD) (Oxoid code CM733, Oxoid, Basingstoke, UK) and the appropriate dilutions were prepared. Total viable counts (TVC) were enumerated by spread plating onto plate count agar (PCA) (Oxoid, Basingstoke, UK), after aerobic incubation at $30{ }^{\circ} \mathrm{C}$ for $48 \mathrm{~h}$. Lactic acid bacteria were enumerated on de Man Rogosa and Sharp agar (MRS) (Oxoid, Basingstoke, UK) by pour plating and incubating at $30^{\circ} \mathrm{C}$ for 72 hours. Enterobacteriaceae were enumerated onto Violet Red Bile Glucose Agar (VRBGA) (Oxoid, Basingstoke, UK) by pour plating and incubating at $37^{\circ} \mathrm{C}$ for 72 hours. Yeasts and moulds were enumerated on Rose-Bengal Chloramphenicol agar (Oxoid, 
Basingstoke, UK) with incubation at $25^{\circ} \mathrm{C}$ for 72 and 120 hours. Each sample was plated in duplicate and the results (the mean of the two plates) were expressed as $\log _{10} \mathrm{CFU} / \mathrm{ml}$ of juice.

\subsection{In vitro digestion model}

175 In order to investigate the cytoprotective effect against $\mathrm{H}_{2} \mathrm{O}_{2}$-induced oxidative stress of the bioaccessible fractions of the two types of juices on Caco-2 cells, tomato juice samples after conventional and microwave pasteurisation (day 0 ) were subjected to a simulated in vitro digestion coupled with Caco-2 cells. Juice samples were weighed in amber glass tubes and subjected to a simulated human gastric and small intestinal digestion based on the method described by Hedrén et al. (2002) and Colle, Van Buggenhout, Van Loey \& Hendrickx, (2010) with modifications, in order to obtain the bioaccessible fraction of the tomato juices. All steps were carried out under dimmed light. The digests were centrifuged at $5000 \times \mathrm{g}$ for $60 \mathrm{~min}$ at $4^{\circ} \mathrm{C}$ to separate the soluble juice fraction, followed by filtration using $0.22 \mu \mathrm{m}$ membrane filters (Millipore, UK). Samples were stored in amber tubes at $-80^{\circ} \mathrm{C}$ under nitrogen until further analysis. In order to ensure the inactivation of enzymes, all digests were heated in a water bath for $4 \mathrm{~min}$ at $100^{\circ} \mathrm{C}$ and then cooled before they were used for incubation with the Caco-2 cells (Cilla et al. 2008).

\subsection{Caco-2 cells culture}

Human intestinal Caco-2 cells (American Type Culture Collection (ATCC) were cultured in medium comprising Minimum Essential Medium (MEM; Life Technologies, U.K.). Cultures were maintained according to Cilla et al. (2008). For the assays, Caco-2 cells were seeded onto 24-well plates, at a density of $1 \times 10^{5}$ cells with $1 \mathrm{ml}$ of MEM and the culture medium was changed every three days. Twenty one days after confluency, the culture medium was removed from the wells and the cell monolayers were washed with phosphate buffered saline 

heated to $37^{\circ} \mathrm{C}$. The cells were pre-incubated $\left(37^{\circ} \mathrm{C} / 5 \% \mathrm{CO}_{2} / 95 \% \mathrm{RH}\right)$ for $24 \mathrm{~h}$ with the bioaccessible fractions of the tomato juice samples, with a ratio of fraction to culture media of $1: 1(\mathrm{v} / \mathrm{v})$ in order to preserve cell viability. Afterwards, the MEM was removed and the cells were washed with PBS. The induction of oxidative stress was carried out by exposure to a $5 \mathrm{mM} \mathrm{H} \mathrm{H}_{2}$ solution in MEM for $1 \mathrm{~h}\left(37^{\circ} \mathrm{C} / 5 \% \mathrm{CO}_{2} / 95 \% \mathrm{RH}\right)$.

201

202

\subsection{Cell viability assay}

The alamarBlue assay was used to determine cell viability of Caco-2 cells after preincubation with bioaccessible fractions of the tomato juices and also to establish the relative cytotoxicity of different concentration of $\mathrm{H}_{2} \mathrm{O}_{2}$ on Caco-2 cells. Briefly, the medium in the 24-well plates was replaced with a $10 \% \mathrm{v} / \mathrm{v}$ alamarBlue ${ }^{\circledR}$ in media solution. $100 \mu \mathrm{L}$ of the medium was added to 4 wells of the 96 -well plate for control measurement. $100 \mu \mathrm{L}$ of alamarBlue ${ }^{\circledR}$ was added to every well of the 24-well plate. Both the 24 and 96 -well plates were incubated at $37^{\circ} \mathrm{C} / 5 \% \mathrm{CO}_{2}$ for $4 \mathrm{~h} .100 \mu \mathrm{L}$ from each 24 -well plate were transferred into the 96 well plate. Absorption was measured at 570 and $600 \mathrm{~nm}$ using an automatic plate reader (Tecan, Sufire ${ }^{2}$, Reading, UK). Results were calculated according to the manufacturer's manual.

\subsection{Organoleptic analysis}

A hedonic test was conducted with 28 assessors in individual booths, aged between 21 and 60 , who scored the acceptability of various tomato juice attributes using the following scoring system: 1 - dislike extremely to 9 - like extremely. Each assessor was asked the score the following attributes for each sample: sweetness, odour, flavour, acidity, appearance and overall acceptability. Prior to organoleptic panelling, all samples were tested for 
microbiological safety. Samples were served in transparent plastic glass, coded with three digit random numbers. Organoleptic analysis took place in the sensory suite at College of Agriculture Food and Rural Enterprise.

\subsection{Data analysis}

The experiment was performed in two different occasions in order to obtain two independent trials. Differences between treatments were assessed with two way analysis of variance (ANOVA) followed by Tukey’s post hoc test. One way analysis of variance was used to determine between treatments for the organoleptic analysis and alamarBlue assay. A significance level of $\mathrm{p}<0.05$ was used for comparisons between treatments and storage time.

\section{RESULTS AND DISCUSSION}

\subsection{Characterisation of treated tomato juice after processing and during storage}

The moisture content immediately after processing for the $\mathrm{CP}$ and $\mathrm{MVH}$ pasteurised juice was $96.10 \pm 0.20 \%$ and $96.47 \pm 0.10 \%$, respectively. The soluble solids content was 2.25 ${ }^{\circ}$ Brix for both juices and this remained stable during storage. There was no significant difference in titratable acidity (0.35-0.44 g citric acid/100g) or $\mathrm{pH}$ values (4.20-4.26) between the two processing technologies and storage time had no significant effect on these parameters. Limited or no effects on $\mathrm{pH}$ and soluble solid values has also been reported in similar studies with orange juice processed with high intensity pulsed electric fields and conventional thermal treatments (Yeom, Streaker, Zhang \& Min, 2000; Elez-Martinez, Soliva-Fortuny, and Martin-Belloso, 2006). Both redness (a*; $1.96 \pm 1.07$ and $1.48 \pm 0.30$ for the CP and MVH pasteurised tomato juice, respectively) and chroma values (C; $7.44 \pm$ 
2432.24 and $7.31 \pm 0.48$ for the $\mathrm{CP}$ and $\mathrm{MVH}$ pasteurised tomato juice, respectively) of the

244 tomato juices after processing (day 0 ) were quite low compared to commercial

245 conventionally pasteurised tomato juice (Sánchez-Moreno, Plaza, de Ancos and Cano 2006)

246 which is attributed to the specific tomato variety that was used to prepare the juice in this

247 study. All colour parameters studied did not differ significantly between the two processing 248 technologies $(\mathrm{p}>0.05)$ and during storage. Cloudiness of the two types of juices was also 249 evaluated during storage (Fig. 2). Fruit juices are comprised of the pulp (insoluble phase) 250 dispersed in a viscous solution (i.e. the serum). Cloudiness is related to the suspension of 251 particles in the serum which are comprised of proteins, pectin, lipids, hemicellulose, cellulose 252 and other minor components (Chou \& Kokini, 1987). Cloudiness was found to be significantly higher for MVH tomato juice ( $<$ 0.05) (Fig. 2). Smaller suspended particles in the serum of the CP juice allow more light to pass through, which results to lower absorbance values and cloudiness (Kubo, Augusto, Cristianini 2013). Cloudiness was gradually reduced for both juices during storage until day 14. Subsequently, cloudiness was stabilised for MVH juice and decreased further for the CP juice until day 28. The progressive reduction in cloudiness during storage was probably due to the precipitation of larger size pulp particles as well as polymerisation of phenolic compounds and proteins (Cao, Bi, Huang, $\mathrm{Wu}, \mathrm{Hu} \& \mathrm{Liao}$ 2012). The difference in the stabilisation and cloudiness values observed may indicate differences in the microstructure of the two juices. Figure 3 illustrates the microstructures of tomato juice by means of optical microscopy. Images of non-treated tomato juice presented intact cells containing carotenoid crystals within them. The images of $\mathrm{CP}$ and $\mathrm{MVH}$ pasteurised samples presented broken cells with internal components within the broken cells and also outside suspended on the juice serum. In general, a higher number of broken cells were observed in MVH samples which means more antioxidant compounds could be released and are available for absorption. 


\subsection{Radical scavenging capacity of tomato juice during storage}

269 The total antioxidant capacity of $\mathrm{CP}$ and $\mathrm{MVH}$ pasteurised tomato juice was determined by means of the ABTS and ORAC assays (Table 1). The ABTS value for the MVH juice was significantly higher compared to the $\mathrm{CP}$ one at day 0 of storage $(\mathrm{p}<0.05)$. ORAC values showed no statistically significant differences between the two processing technologies at day 0. An increased retention of antioxidant capacity during microwave processing has been shown in other studies. The work of Kaur, Khurdiya, Pal \& Kapoor, (1999) has shown that microwave processed tomato juice had a higher retention of ascorbic acid, total carotenoids and lycopene contents compared to conventionally processed juice. Igual, García-Martínez, Camacho \& Martínez-Navarrete, (2010) have also found a higher retention of ascorbic acid in grapefruit juice pasteurised with the use of microwaves compared to a conventional heat pasteurisation. However, microwave and conventional pasteurisation caused a similar decrease of the total phenol content and DPPH values. Microwave processing of kiwifruit puree has also been found to result in significantly higher antioxidant activity compared to conventional heat treatment (Benlloch-Tinoco, Igual, Salvador, Rodrigo \& MartínezNavarrete 2014). In this study, differences between ABTS and ORAC results were expected because of the different nature of the two methods. ABTS is an electron transfer method which measures the capacity of an antioxidant to reduce an oxidant, whereas ORAC is based on hydrogen atom transfer in which antioxidant and substrate compete for thermally generated peroxyl radicals. The higher antioxidant capacity observed here determined with ORAC versus ABTS has also been found in other studies (Zulueta Esteve and Frígola 2009). The total antioxidant capacity of the juices showed fluctuations throughout the entire period of storage (Table 1). It is noteworthy that these fluctuations in both types of tomato juice were quite similar. Both ABTS and ORAC values showed a significant increase in antioxidant capacity at the end of the storage period for CP but not for MVH juice. These 
differences are not usual. It has been shown that flavonoids, vitamins and total phenol content, responsible for total antioxidant capacity can undergo fluctuations in fruit juices during cold storage (Del Caro, Piga, Vacca, Agabbio, 2004; Klimczak, Malecka, Szlachta \& Gliszczynska-Swiglo, 2007).

\subsection{Effect of processing on the microbiological characteristics during storage}

The effect of both types of processing on total viable counts (TVC), lactic acid bacteria (LAB), Enterobacteriaceae and yeasts and moulds counts of tomato juice during storage at $4^{\circ} \mathrm{C}$ for 56 days, was investigated. Immediately after processing (day 0 of storage) both types of tomato juice had counts below the limit of detection for all the microorganisms tested. Throughout storage, LAB, Enterobacteriaceae and yeasts and moulds counts remained below the detection limit for both juices. Only TVC counts were detected on day $28(2.13 \pm 0.33$ and $2.00 \pm 0.33 \log \mathrm{CFU} / \mathrm{ml}$ for $\mathrm{CP}$ and $\mathrm{MVH}$ juices, respectively) which remained stable until day 56 (2.16 \pm 0.25 and $2.05 \pm 0.12 \log \mathrm{CFU} / \mathrm{ml}$ for CP and MVH juices, respectively), with no significant differences between storage days $(\mathrm{p}>0.05)$ or between processing technologies $(\mathrm{p}>0.05)$. The results from the present study are in accordance with the results of Hsu, Tan and Chi (2008) that showed LAB, Enterobacteriaceae and yeasts and moulds counts remained below the detection limit in thermally pasteurised tomato juice for at least 28 days of refrigerated storage. The low microbial counts during storage are consistent with the stable $\mathrm{pH}$ values observed for both types of tomato juice since a reduction in $\mathrm{pH}$ may be attributable to organic acid production as a result of microbial growth. Even though the heating mechanism of the two technologies is different the results reveal a very similar effect on the microbial stability during storage. Microwave volumetric heating appears to be equally as effective for microbial inactivation and the prolongation of the shelf life of tomato juice, as the conventional technology. 


\subsection{Protective effect against induced oxidation after in vitro digestion}

319 During digestion, antioxidant and other functional constituents, present in the food being 320 digested, could be released and metabolised or remain within the food. Therefore, it is important to quantify the fraction of the ingested antioxidants which are available for use by the body (Wootton-Beard, Moran \& Ryan 2011). This is referred to as bioaccessibility and represents the quantity of nutrients which are released from the food matrix and are accessible for transport into the mucosa (Hedrén et al. 2002). Recently, several studies have used in vitro digestion models to determine the bioaccessibility of several nutrients such as lycopene (Colle et al. 2010), and $\beta$-carotene (Knockaert et al. 2011) after processing with novel or conventional technologies. These in vitro models are usually coupled with chromatographic or spectrophotometric methods. In this study we evaluated the antioxidant effect of the two juices by combining an in vitro digestion model with an intestinal epithelia model (i.e. Caco-2 cells) in order to offer a more realistic view on what is occurring during digestion. To the best of our knowledge this is the first study that determined the effect of commercial scale processing technologies using an in vitro digestion/Caco-2 cells model. Figure 4 illustrates the effect that $\mathrm{CP}$ and $\mathrm{MVH}$ pasteurised tomato juice had against $\mathrm{H}_{2} \mathrm{O}_{2}$ induced oxidative stress in Caco-2 cells, after in vitro digestion. Incubation of Caco-2 cells with a $5 \mathrm{mM}$ solution of $\mathrm{H}_{2} \mathrm{O}_{2}$ resulted in a significant reduction in Caco-2 viability (79.77 \pm $1.67 \%$ compared to the control) which is consistent with the study of Cilla et al. (2008) who found a similar effect of $\mathrm{H}_{2} \mathrm{O}_{2}$ on Caco-2 cells. After $\mathrm{H}_{2} \mathrm{O}_{2}$ diffuses to mitochondria, it has been found to cause a loss of mitochondrial integrity and function and ultimately cell death (Mronga, Stahnke, Goldbaum, \& Richter-Landsberg, 2004). In this study, for the Caco-2 cell cultures that were pre-incubated with bioaccessible fractions of CP and MVH tomato juices the AlamarBlue assay showed increased cell viability for both types of processed juices. Tomato is considered a rich source of several antioxidants, such as ascorbic acid, vitamin E, 
carotenoids, flavonoids and phenolic acids (George, Kaur, Khurdiya, \& Kapoor, 2004). Thus,

344 it appears that the antioxidants present in the bioaccessible fractions of the tomato juices where able to partially prevent the cytotoxic effect induced by $\mathrm{H}_{2} \mathrm{O}_{2}$ on the Caco-2 cells. Laparra, Alegría, Barberá \& Farré (2008) reported that the antioxidant compounds present in fruit beverages consisting of grape, orange and apricot concentrates, after in vitro digestion, reduced the cytotoxic effect of $\mathrm{H}_{2} \mathrm{O}_{2}$ induced oxidative stress on Caco-2 cell viability, as determined by the MTT (3-[4,5-dimethylthiazol-2-yl]-2,3-diphenyl tetrazolium bromide) assay. Bellion, Digles, Will, Dietrich, Baum, Eisenbrand \& Janzowski (2010) found that extracts from apple juice, apple pomace extraction juice and apple peel were able to significantly reduce DNA damage induced in Caco-2 cells with apple peel extract being the most effective. Although, in this study both juices exerted a cytoprotective effect against $\mathrm{H}_{2} \mathrm{O}_{2}$ induced oxidation, the MVH juice showed a significantly higher protective effect compared to the conventional one $(\mathrm{p}<0.05)$ which may indicate a higher antioxidant capacity of the microwave processed juice. The protective effects of tomato products might be derived from the antioxidant components that can prevent cell damage by means of synergistic interactions (Friedman, 2002; George et al., 2004). Although the higher cytoprotective effect observed for the MVH juice might be explained by the higher amounts of antioxidant in the bioaccessible fractions, it could also be due to other reasons. Recently, the relationship between food microstructure and the food's nutritional value has been highlighted. The study of Lemmens, Van Buggenhout, Oey, Van Loey, \& Hendrickx, (2009) showed that the microstructure characteristics of carrot tissue affect hardness which was found to be negatively correlated to $\beta$-carotene in vitro bioaccessibility. Colle et al. (2010) found that for high pressure homogenisation increasing the pressure levels resulted in the formation of a stronger fibre network in tomato pulp which leads to the decrease of lycopene in vitro bioaccessibility by making it less approachable to digestive enzymes and bile salts. 
Therefore, the increased protective effect observed in this study for the MVH tomato juice might also be derived by the increased bioaccessibility of certain nutrients present in the juice. The differences in cloudiness levels between the two tomato juices might be an indicator of their different microstructure however more in depth analysis is needed to conclusively state this. In this regard, parameters such as the temperature kinetics of the heat treatment play an important role in lycopene bioaccessibility as rapid heating of tomato puree (with the use of a microwave oven) can lead to higher bioaccessibility compared to a slow temperature increase (Page, Van Stratum, Degrou \& Renard, 2012). A comparison to a conventional continuous flow system will give further evidence on the effect of processing on antioxidant bioaccessibility.

\subsection{Organoleptic analysis}

Since the food industry is showing interest in the adoption of novel processing technologies in order to meet the needs of consumers investigating the impact that these technologies have on the acceptability of processed products is essential. The organoleptic analysis results of the pasteurised juices are presented samples in Fig. 4. In general, both the CP and MVH tomato juices had similar scores. The results of the analysis showed that no differences between the two juices could be distinguished by the organoleptic panel for the odour, acidity, flavour and sweetness attributes. A statistically significant difference was observed for the appearance attribute with the CP juice scoring slightly higher. However, the overall acceptability (p > 0.05) did not differ significantly between the two types of juice. The lower scores for appearance of MVH juice could be explained by the higher cloudiness values observed (Fig. 2). Similar results were found by Valero et al. (2000) who stated that there were no perceivable differences in organoleptic characteristics between microwave and conventionally processed milk in a heat exchanger both after processing and during storage. 
It has also been reported that microwave processing can result in improved organoleptic characteristics. The study of Benlloch-Tinoco et al. (2014) demonstrated that based on all the organoleptic characteristics tested, panellists showed a clear preference to the microwave processed kiwifruit puree compared to conventional heat treated one in a batch retort. In the present study, given that there was no difference in the overall acceptability in almost all attributes evaluated, it is concluded that the continuous microwave processing is a promising and viable alternative to conventional pasteurisation. More work comparing the MVH system to an industrial scale conventional continuous flow pasteuriser will provide more information on the potential advantages of this novel technology.

402

\section{CONCLUSIONS}

404

Tomato juice pasteurisation with the novel industrial scale continuous microwave system had very similar physicochemical and microbial characteristics compared with the conventional pasteurisation, during refrigerated storage. The antioxidant capacity measured with the ABTS assay, but not with ORAC, immediately after treatment was higher for the MVH juice compared to the CP one. However, antioxidant capacity of the juices during storage was very similar. Moreover, bioaccessible fractions of the MVH juice were able to provide a significantly higher protective effect against $\mathrm{H}_{2} \mathrm{O}_{2}$ induced oxidation in Caco-2 cells. The organoleptic trial showed no significant differences between the two juices for almost all attributes evaluated. Microwave processing with the use of this novel continuous microwave volumetric heating system appears to a viable alternative for tomato juice pasteurisation since 414 it can produce a physicochemically and microbiologically stable product with higher antioxidant capacity, in significantly reduced processing time. The application of new generation microwave technologies in food processing has not reached its full potential so 417 far, however, it shows promise in delivering a range of products and ensuring microbiological 
418 safety without compromising quality. Given that industrial scale equipment was used, the 419 results from this study should facilitate the adoption of this technology by the industry.

420

\section{Conflict of interest statement}

422 The authors declare no conflict of interest

423

424 Acknowledgements

425 The research leading to these results has received funding from the European Union's 426 Seventh Framework Programme for research, technological development and demonstration 427 under grant agreement No. 289262. Theme KBBE.2011.2.1-01, research project STARTEC: 428 "Decision Support Tools to ensure safe, tasty and nutritious Advanced Ready-to-eat foods for 429 healthy and vulnerable Consumers”. We would like to thank Alan Johnson and Fiona 430 Ferguson at CAFRE for their assistance during the processing of the tomato juice. 
Figure 1. Schematic representation of the continuous flow microwave system.

441

442 Figure 2. Cloudiness values of conventionally and microwave pasteurised tomato juice 443 during storage at $4^{\circ} \mathrm{C}$. Results are expressed as means \pm SD $(n=4)$.

Figure 3. Typical light microscopic pictures (x10) of conventionally and microwave pasteurised tomato juice after processing - day $0(\mathrm{CP}=$ conventional, $\mathrm{MVH}=$ Microwave

447 volumetric heating).

Figure 4. Caco-2 cell cultures pre-incubated for $24 \mathrm{~h}$ with bioaccessible fractions of conventional and microwave pasteurised tomato juice and exposed to $5 \mathrm{mM} \mathrm{H}_{2} \mathrm{O}_{2}$. Results

451 are expressed as means \pm SD $(n=6)$ of the control $(100 \%)$. Different lower case letters 452 denote statistically significant differences $(\mathrm{p}<0.05)$.

453

454

455

Figure 5. Organoleptic comparison of conventionally and microwave pasteurised tomato 456 juice (after processing - day 0) 
1. Adekunte, A. O., Tiwari, B. K., Cullen, P. J., Scannell, A. G. M., \& O’Donnell, C. P. (2010). Effect of sonication on colour, ascorbic acid and yeast inactivation in tomato juice. Food Chemistry, 122, 500-507.

2. AMT 2015. Advanced microwave systems. URL http://www.advancedmicrowavetechnologies.com/. Accessed 05.01.2015

3. Bayod, E., Mansson, P., Innings, F., Bergenstahl, B., \& Tornberg, E. (2007). Low shear rheology of concentrated tomato products. Effect of particle size and time. Food Biophysics, 2, 146-157.

4. Beecher, G. R. (1998). Nutrient content of tomatoes and tomato products. Proceedings of the Society for Experimental Biology and Medicine, 218, 98-100.

5. Bellion P., Digles J., Will F., Dietrich H., Baum M., Eisenbrand G., \& Janzowski C. (2010). Polyphenolic Apple Extracts: Effects of Raw Material and Production Method on Antioxidant Effectiveness and Reduction of DNA Damage in Caco-2 Cells. Journal of Agriculture and Food Chemistry, 58, 6636-6642.

6. Benlloch-Tinoco M., Igual M., Salvador, A., \& Rodrigo d., \& Martínez-Navarrete, N. (2014). Quality and Acceptability of Microwave and Conventionally Pasteurised Kiwifruit Puree. Food and Bioprocess Technology, 7, 3282-3292.

7. Cao, X., Bi, X., Huang, W., Wu, J., Hu, X., Liao, X., (2012). Changes of quality of high hydrostatic pressure processed cloudy and clear strawberry juices during storage. Innovative Food Science \& Emerging Technologies, 16, 181-190.

8. Chandrasekaran, S., Ramanathan, S., \& Basak T. 2013. Microwave food processingA review. Food Research International, 52, 243-261.

9. Chou, T.D., \& Kokini. J.L. (1987) Rheological properties and conformation of tomato paste pectins, citrus and apple pectins. Journal of Food Science, 52, 1658-1664. 
10. Cilla, A., Laparra, J. M., Alegria, A., Barbera, R., \& Farre, R. (2008). Antioxidant effect derived from bioaccessible fractions of fruit beverages against $\mathrm{H}_{2} \mathrm{O}_{2}$-induced oxidative stress in Caco-2 cells. Food Chemistry, 106, 1180-1187.

11. Colle, I., Van Buggenhout, S., Van Loey, A., \& Hendrickx, M. (2010). High pressure homogenization followed by thermal processing of tomato pulp: Influence on microstructure and lycopene in vitro bioaccessibility. Food Research International, 43, 2193-2200.

12. Del Caro, A., Piga, A., Vacca, V., Agabbio, M., 2004. Changes of flavonoids, vitamin $\mathrm{C}$ and antioxidant capacity in minimally processed citrus segments and juices during storage. Food Chemistry, 84, 99-105.

13. Elez-Martinez, P., Soliva-Fortuny, R.C., \& Martin-Belloso, O. (2006). Comparative study on shelf-life of orange juice processed by high intensity pulsed electric fields or heat treatments. European Food Research and Technology, 222, 321-329.

14. Friedman, M. (2002). Tomato glycoalkaloids: Role in the plant and in the diet. Journal of Agriculture and Food Chemistry, 50, 5751-5780.

15. Fu, Y.C. (2004). Fundamentals and industrial applications of microwave and radio frequency in food processing. In J. S. Smith \& Y. H. Hui (Eds.), Food processing: principles and applications (pp. 79-100). Iowa: Blackwell.

16. George, B., Kaur, C., Khurdiya, D. S., \& Kapoor, H. C. (2004). Antioxidants in tomato (Lycopersium esculentum) as a function of genotype. Food Chemistry, 84, 4551.

17. Hedrén, E., Diaz, V., \& Svamberg, U. (2002). Estimation of carotenoid accessibility from carrots determined by an in vitro digestion method. European Journal of Clinical Nutrition, 56, 425-430. 
18. Hong X., \& Jun Wang, J. (2014). Use of Electronic Nose and Tongue to Track Freshness of Cherry Tomatoes Squeezed for Juice Consumption: Comparison of Different Sensor Fusion Approaches. Food Bioprocess Technology, In press.

19. Hsu, K. C., Fa-Jui Tan, F.-J., \& Chi, H.-Y. (2008). Evaluation of microbial inactivation and physicochemical properties of pressurized tomato juice during refrigerated storage. $L W T$, 41, 367-375.

20. Huang, D., Ou, B., Hampsch-Woodill, M., Flanagan, J. D., \& Prior R.L. (2002). High-Throughput Assay of Oxygen Radical Absorbance Capacity (ORAC) Using a Multichannel Liquid Handling System Coupled with a Microplate Fluorescence Reader in 96-Well Format. Journal of Agricultural and Food Chemistry, 50, 44374444.

21. Igual, M., García-Martínez, E., Camacho, M. M., \& Martínez-Navarrete, N. (2010). Effect of thermal treatment and storage on the stability of organic acids and the functional value of grapefruit juice. Food Chemistry, 118, 291-299.

22. Igual, M., García-Martínez, E., Camacho, M.M., \& Martínez-Navarrete, N. (2011). Changes in flavonoid content of grapefruit juice caused by thermal treatment and storage. Innovative Food Science and Emerging Technologies, 12, 153-162.

23. Kaur, C., Khurdiya, D. S., Pal, R. K., Kapoor, H. C. (1999). Effect of Microwave Heating and Conventional Processing on the Nutritional Qualities of Tomato Juice. Journal of Food Science and Technology, 36, 331-333.

24. Klimczak, I., Malecka, M., Szlachta, M., Gliszczynska-Swiglo, A., 2007. Effect of storage on the content of polyphenols, vitamin $\mathrm{C}$ and the antioxidant activity of orange juices. Journal of Food Composition and Analysis, 20, 313-322. 
25. Knockaert, G., Roeck, A.S., Lemmens, L., Van Buggenhout, S., Hendrickx, M., \& Van Loey, A., (2011). Effect of thermal and high pressure processes on structural and health-related properties of carrots (Daucus carota). Food Chemistry, 125, 903-912.

26. Kubo, M. T. K. K., Augusto, P. E. D \& Cristianini, M. (2013). Effect of high pressure homogenization (HPH) on the physical stability of tomato juice. Food Research International, 51, 170-179.

27. Laparra, J. M., Alegría, A., Barberá, R., \& Farré, R. (2008). Antioxidant effect of casein phosphopeptides compared with fruit beverages supplemented with skimmed milk against $\mathrm{H}_{2} \mathrm{O}_{2}$-induced oxidative stress in Caco-2 cells. Food Research International, 41, 773-779.

28. Lemmens, L., Van Buggenhout, S., Oey, I., Van Loey, A., \& Hendrickx, M. (2009). Towards a better understanding of the relationship between the [beta]-carotene in vitro bioaccessibility and pectin structural changes: A case study on carrots. Food Research International, 42, 1323-1330.

29. Miller, N. J., Rice-Evans, C., Davies, M. J., Gopinathan V., \& Milner, A. (1993). A novel method for measuring antioxidant capacity and its application to monitoring the antioxidant status in premature neonates. Clinical Science (Lond), 84, 407-12.

30. Mronga, T., Stahnke, T., Goldbaum, O., \& Richter-Landsberg, C. (2004). Mitochondrial pathway is involved in hydrogen-peroxide induced apoptotic cell death of oligodendrocytes. Glia, 46, 446-455.

31. Odriozola-Serrano, I., Soliva-Fortuny, R., Hernandez-Jover, T., \& Martin-Belloso, O. (2009). Little effect of high intensity pulsed electric fields and thermal treatments on physical properties (pH and soluble solids) of orange and tomato juice. Food Chemistry, 112, 258-266. 
32. Page, D., Van Stratum, E., Degrou, A., \& Renard, C. M. G. C. (2012). Kinetics of temperature increase during tomato processing modulate the bioaccessibility of lycopene. Food Chemistry, 135, 2462-2469.

33. Re, R., Pellegrini, N., Proteggente, A., Pannala, A., Yang, M., \& Rice-Evans, C. (1999) Antioxidant activity applying an improved ABTS radical cation decolorization assay. Free Radical Biology and Medicine, 26, 1231-1237.

34. Sánchez-Moreno, C., Plaza, L., de Ancos, B., \& Cano, M.P. (2006). Nutritional characterisation of commercial traditional pasteurised tomato juices: carotenoids, vitamin C and radical-scavenging capacity. Food Chemistry, 98, 749-756.

35. Señorans, F. J., Ibáñez, E., \& Cifuentes, A. (2003). New trends in food processing. Critical Reviews in Food Science and Nutrition, 43, 507-526.

36. Silva, V. M., Sato, A. C. K., Barbosa, G., Dacanal, G., Ciro-Velásquez, H. J., \& Cunha, R. L. (2010). The effect of homogenisation on the stability of pineapple pulp. International Journal of Food Science and Technology, 45, 2127-2133.

37. Valero, E., Villamiel, M., Sanz, J., \& Martínez-Castro, I. (2000). Chemical and sensorial changes in milk pasteurised by microwave and conventional systems during cold storage. Food Chemistry, 70, 77-81.

38. Willcox, J. K., Catignani, G.L., \& Lazarus, S. G. (2003). Tomato and cardiovascular health. Critical Reviews in Food Science and Nutrition, 43, 1-18.

39. Yeom, H. W., Streaker, C. B., Zhang, Q. H., \& Min, D. B. (2000). Effects of pulsed electric fields on the quality of orange juice and comparison with hat pasteurization. Journal of Agricultural and Food Chemistry, 48, 4597-4605.

40. Zulueta, A., Esteve, M. J. Frígola, A. (2009). ORAC and TEAC assays comparison to measure the antioxidant capacity of food products. Food Chemistry, 114, 310-316. 